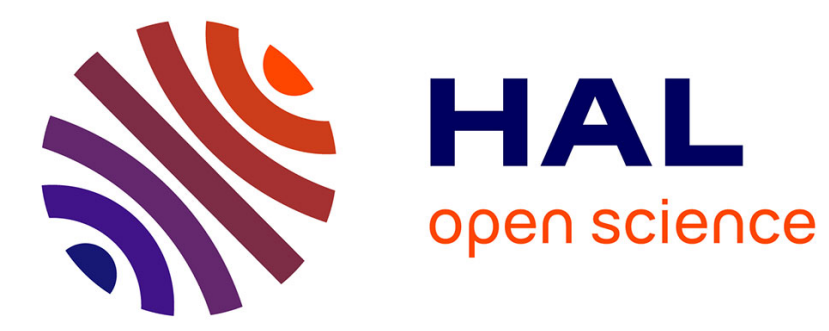

\title{
The FA Analysis of Emotional Values and Practical Reasons
}

Stéphane Lemaire

\section{To cite this version:}

Stéphane Lemaire. The FA Analysis of Emotional Values and Practical Reasons. Dialogue: Canadian Philosophical Review / Revue canadienne de philosophie, 2012, 51, pp.31-53. 10.1017/S0012217312000224 . hal-02972101

\section{HAL Id: hal-02972101 \\ https://hal-univ-rennes1.archives-ouvertes.fr/hal-02972101}

Submitted on 23 Oct 2020

HAL is a multi-disciplinary open access archive for the deposit and dissemination of scientific research documents, whether they are published or not. The documents may come from teaching and research institutions in France or abroad, or from public or private research centers.
L'archive ouverte pluridisciplinaire HAL, est destinée au dépôt et à la diffusion de documents scientifiques de niveau recherche, publiés ou non, émanant des établissements d'enseignement et de recherche français ou étrangers, des laboratoires publics ou privés. 
This is an Author's Original Manuscript of an article published by Cambridge University Press in Dialogue 51 (2012), pp. 31- 53 and available online at

https://doi.org/10.1017/S0012217312000224

The FA Analysis of Emotional Values and Practical Reasons ${ }^{*}$

Stéphane Lemaire

Université de Rennes 1

UFR de philosophie - Université de Rennes 1

Campus de Beaulieu - bât. 32B

263, avenue du Général Leclerc - CS 74205

35042 Rennes cedex

France 


\begin{abstract}
Confronted with the wrong kind of reason problem, several proponents of the fitting attitude analysis of emotional values have argued in favor of an epistemic approach. In such a view, an emotion fits its object because the emotion is correct. However, I argue that we should reorient our search towards a practical approach because only practical considerations can provide a satisfying explanation of the fittingness of emotional responses. This practical approach is partially revisionist, particularly because it is no longer an analysis of final value, and because it is relativistic.
\end{abstract}

\title{
Résumé
}

Confronté au problème posé par les raisons non pertinentes, plusieurs défenseurs de l'analyse des valeurs émotionnelles en termes d'attitudes appropriées ont proposé une approche épistémique. Selon celle-ci, une émotion est appropriée parce qu'elle est correcte. Je soutiens cependant que nous devrions plutôt orienter nos recherches dans le sens d'une approche pratique car seule les considérations pratiques sont en mesure d'expliquer de façon satisfaisante le caractère appropriée d'une émotion pertinent pour cette analyse. Une telle approche sera partiellement révisionniste en particulier parce qu'elle n'est plus une analyse de valeur finale et parce qu'elle est relativiste. 


\section{Introduction}

In the fitting-attitude analysis (hereafter FAA) of values, $\mathrm{X}$ is valuable if and only if there is a certain attitude $\mathrm{Y}$ that fits $\mathrm{X}$. For instance, the FAA of admirable could be given by the bivalence: $\mathrm{X}$ is admirable if and only if admiration fits $\mathrm{X}$.

The analysis may be understood as conceptual or metaphysical. In this paper, I will primarily be concerned by conceptual analysis, but because the goal of this conceptual analysis is to better understand what values are, I will also discuss the metaphysical reading of the analysis.

There are disagreements and difficulties with two aspects of this analysis. The first set of difficulties concerns the attitudes that are relevant in the analysis. It has been argued that no attitude or set of attitudes can possibly fulfill the relevant role. ${ }^{1}$ However, I will not address this problem, because this paper concentrates exclusively on the FAA of what we may call emotional value concepts, that is, evaluative concepts that are lexically connected to concepts of emotion. Since this class encompasses evaluative concepts such as admirable, fearsome, amusing or funny, enviable, despicable, shameful, etc., there is no doubt that the attitude that must appear in the analysans is the corresponding emotion. It is difficult to believe that the relevant attitude to analyze the value "admirable" could be anything but admiration. Thus, I take it that emotions are the only possible relevant attitudes, if indeed some attitudes are able to fulfill the relevant role, and I leave unanswered the question of whether these attitudes are indeed able to fulfill their role in the FAA. 
Instead, the aim of the paper is to concentrate on the second set of difficulties that concerns the term "fitting", its interpretation or replacement when we consider these emotional values. Aside from "fitting", there is a broad spectrum of possible alternatives: "appropriate", "correct", or even "true" have been suggested in the literature. ${ }^{2}$ We may also rephrase the analysis and propose that something is valuable if and only if there is an attitude that one ought to have, that is required, or that one has a reason to have. ${ }^{3}$ In any case, one of the major challenges in the choice of a version of this analysis is what has been termed the wrong kind of reason problem (henceforth the WKR problem) after Rabinowicz and Ronnow-Rasmussen. ${ }^{4}$ The problem can easily be stated using the notion of reason. Suppose that a mighty demon threatens to punish me if I do not admire him. In such a situation, I certainly have a reason to admire him, but this reason is not the one that should appear in the analysis of the concept admirable, since a mighty demon who threatens me does not thereby become admirable. Hence, a FAA relying on reasons must provide a criterion in order to sort out which are the right kind of reasons in the analysis. Analogously, any notion that purports to replace the notion of fit in a FAA must be such that a threatening demon does not make admiration fitting.

The demon example triggers the strong intuition that we can distinguish, at least case by case, the wrong from the right kind of reasons, or that we know implicitly the kind of fittingness that appears in the analysis. ${ }^{5}$ Although it has proven very difficult to produce an explicit criterion that avoids every possible counter-example, the case of the mighty demon suggests that the right kind of reasons must not encompass prudential reasons. Other examples pull in a similar direction. For example, we may have a moral reason not to laugh at a joke at a funeral even if the joke that our neighbor tells us is very 
funny. Denying this possibility would represent a questionable kind of moralism. Therefore, taking the lead from these examples, it is tempting to suggest that the normative concept that is part of the analysis must be distinct from both prudential rationality and moral normativity. D'Arms and Jacobson adopt such a view when they write: "we will argue that moral and prudential considerations about an emotion are irrelevant to the issue at hand," notion of fittingness. Now, there have been several attempts to give, for all values, a precise account of this independence requirement. Parfit ${ }^{7}$ has suggested that we should distinguish between state-given reasons and object-given reasons. Skorupski ${ }^{8}$ distinguishes between "practical reasons" and "evaluative reasons". Lang ${ }^{9}$ has proposed that the "reason to have that attitude towards X should still be reason-giving in the absence of the benefits to us of having the attitude towards X." ${ }^{10}$ Olson ${ }^{11}$ has first suggested that the "reasons of the right kind are not provided by the consequences of taking up the relevant attitude," an idea also suggested by Stratton-Lake. ${ }^{12}$ He now argues, with Danielson, ${ }^{13}$ that the relevant reasons are "content-reasons", in contrast to "holding-reasons".

Although all of these proposals have failed to provide a satisfying criterion that could distinguish for all values the right kind of reasons, it may seem that they are nevertheless on the right track. In spite of not having yet been able to transform the independence requirement into a criterion, the general idea seems to lead us in the proper direction. On this view, fittingness would be understood as correctness, a notion that would itself have some analogy with, or even be identical to, truth. In fact, this kind of approach goes back to Brentano. He has proposed that the normative notion of fittingness 
should be the notion of correctness, a notion that he sees as fundamentally epistemic and close to truth, albeit different. ${ }^{14}$ Such an epistemic approach is made plausible by the existence of a similar independence requirement that applies to beliefs and to perceptions. Having a certain belief or perception may be useful, even though the belief is false and the perception is in fact an illusion. Thus, there is a way in which beliefs fit by virtue of their correctness and not any practical consideration. Why not then suggest that the relevant reasons in assessing whether an attitude fits a value are also epistemic? Moreover, we will see that such an epistemic approach is made especially plausible when we focus, as is my intention, on emotional value concepts.

Another reason in favor of the independence requirement is that it is vital to the FAA of emotional value concepts, as this analysis collapses if the relevant reasons do not satisfy the independence requirement. To see this, suppose that you accept the reduction of the concept admirable provided by its FAA: $\mathrm{X}$ is admirable if there is a reason to admire X. Suppose, however, that the independence requirement is false and that the relevant reasons are, say, prudential. The immediate consequence is that admirable ceases to be an evaluative concept. Since the FAA now says that " $\mathrm{X}$ is admirable if and only if there are prudential reasons to admire X," to say that something is admirable becomes prudential advice that relies on other values. Therefore, the defense of the FAA of emotional value concepts must adopt something like the independence requirement as a constraint on reasons since if it does not, the analysis is no longer an analysis of value concepts. Notice nevertheless that in the latter case, this would not mean that the FAA is incorrect. It would instead become merely an analysis of a certain set of concepts of instrumental values or of derived norms. 
The aim of this paper, however, is to demonstrate that every account of the FAA of emotional value concepts that adopts this epistemic approach, i.e., that tries to understand fittingness as a kind of correctness, is doomed to fail. Therefore, we should supersede the epistemic approach by a completely different approach to the FAA, which I shall call the practical approach. To the extent that my strategy is not to reject a specific version of the epistemic approach to the FAA but rather this family of accounts, my arguments aim to show that the ideas that ground this epistemic approach to emotional value concepts are mistaken and that we should reorient our search in the direction of a practical approach. In order to do so, I will begin the second section of the paper with a presentation of the epistemic approach in order to show its core tenets and what makes it an especially attractive view when we consider emotional value concepts. In the remainder of the second section, I will then contend that the epistemic approach is unable to fulfill its ambition: that is, to be an account of objective emotional values. In other words, I will show that the epistemic approach is unable to justify the fact that some objects ${ }^{15}$ are objectively amusing, shameful, despicable, etc. The consequence is that the epistemic approach leads the FAA analysis of emotional value concepts to an error theory. Indeed, if no object is, say, objectively amusing, the epistemic approach to the FAA analysis of amusing implies that this emotional evaluative concept has no referent.

The third section then proceeds to show the importance of practical considerations in the FAA of emotional values. To this end, I will point out in the first subsection that part of the appeal that draws us to an epistemic approach relies on turning natural facts into norms. By the same token, this will indicate why practical considerations must be 
relevant. I will then show in the following three subsections that several practical considerations are relevant in explaining the fittingness of emotions. Furthermore, it will become apparent that these practical considerations partly underlie our intuitions about this fittingness. The fourth section describes the consequences of a practical approach to the FAA. First, since the FAA relies on practical considerations, the analysis no longer bears on final value concepts, as we have already shown, but instead on norms derived from practical considerations. Second, for most of these norms, the FAA will be modified by the introduction of a relativizing clause. What is admirable or enviable dependsamong other things - on our emotional dispositions.

\section{Shape and correctness}

\subsection{Emotions involve an assessment of their object}

If we are afraid of an object, it seems to be because we have assessed this object as dangerous. Similarly, if we admire someone, it seems to be because we assess this person as admirable. It is thus very intuitive to think that an emotion always involves an assessment of its object, and most recent philosophical accounts of emotions accept as

much. ${ }^{16}$ Moreover, this is the central tenet of the appraisal theory of emotions ${ }^{17}$ that dominates the research on emotions in the cognitive sciences.

Now, if emotions assess their object, then this assessment may be correct or incorrect. One can assess something as admirable and be correct or mistaken in this assessment: the object that we admire may or not be admirable. Thus, once emotions are acknowledged as assessing their object, we have an interpretation of the notion of 
fittingness as correctness. Although this will not impact our discussion, it is interesting to note that the assessment involved in emotions may take different forms. It may be part of an evaluative assessment of which the subject is not itself aware as some appraisal theorists argue; ${ }^{18}$ it may appear to the subject itself as an evaluative judgment involved in emotions as emotion cognitivists have argued, ${ }^{19}$ or it may even be presented in the content of emotions if it is suggested that emotions present evaluated objects. ${ }^{20}$ On the latter view, for example, envy presents its object as being enviable and shame presents it as being shameful.

Once this much has been accepted, a very intuitive solution to the WKR problem emerges: an emotion fits its object if the object has the evaluative properties that the assessment involved in the emotion has attributed to this very object. This solution is indeed adopted by D'Arms and Jacobson: "When we ask whether an emotion is fitting, in the sense relevant to whether its object is $\mathrm{V}$, we are asking about the correctness of these presentations. ${ }^{, 21}$ It is also adopted by Tappolet and Deonna and Teroni. ${ }^{22}$ Introducing the technical notion of shape, that is the property assessed by an emotion and presented in its content, we may say that for the token of an emotion to be correct, the object of the token emotion must possess the property that is the shape of the emotion type. For instance, an emotion of admiration toward $\mathrm{X}$ is correct if and only if $\mathrm{X}$ has the property of being admirable - which is precisely the shape of admiration. More generally, even if the assessment involved in emotions is not presented in the emotional experience itself, a similar understanding of the fittingness in terms of correctness is available. It is still possible to say that the assessment is correct or incorrect because it suffices that an assessment has taken place, even if it has taken place at a level at which the subject of the 
emotion is not or cannot be aware. In short, because emotions involve an assessment of their object that can be either correct or incorrect, the epistemic approach seems to offer an attractive interpretation of the FAA of emotional value that is able overcome the WKR problem. More specifically, it overcomes the WKR problem because the shape offers a criterion to distinguish the right from the wrong kind of reasons. The only reason for which an emotion fits its object is that the object has the properties that define the shape of this emotion type.

Interestingly, this shape criterion is not reducible to the denial of the relevance of practical considerations in assessing the fittingness of emotions. As D'Arms and Jacobson emphasize, "moral considerations are sometimes relevant to the fittingness of an emotion., ${ }^{23}$ Outrage is fitting if something is outrageous. However, as the earlier funeral example has shown, the fact that it would be immoral to laugh at a joke in some circumstances is irrelevant to the assessment of whether a joke is funny. Now, it is certainly a major advantage of the shape criterion that it accomodates both of these intuitions. On one hand, it excludes practical considerations, as in the funeral example, because the shape of amusement is not practical and is therefore not moral. On the other hand, it allows practical considerations to be relevant when the shape is itself practical, as in the case of outrage. In other words, moral and prudential considerations provide reasons of the right kind for the correctness of an emotion if and only if such considerations are involved in the shape of the emotion.

\subsection{Does shape offer a criterion?}


Let us now assess the epistemic approach to emotional value concepts and the shape criterion. My ambition is to show that even if the epistemic approach is obviously a good strategy for understanding the fittingness of beliefs and ordinary perceptions, this approach to the FAA of emotional value concepts fails because the shape of emotions is unable to determine whether an emotion objectively fits its object. In other words, I contend that, confronted with diverging judgments about what is amusing, shameful, enviable, etc., the shape of emotions is unable to justify the fact that some emotional responses are objectively correct. Therefore, because the epistemic approach is objectivist, the approach is useless. At best, we have an error theory at the conceptual level that it would be best to relinquish in order to look for a better metaphysical description of emotional values. At worst, it is a mistaken metaphysical analysis. Moreover, it follows that the shape criterion does not really deliver a solution to the WKR problem, since it is unable to determine which are the reasons of the right kind.

I will proceed in two stages. In this subsection, I argue that the shape criterion is unable to justify which emotions are objectively fitting. In the subsections that follow, I argue that even if we also rely on our dispositions and on our "discounting practice"24 towards our emotional responses, we cannot do better.

Thus, the aim of this subsection is to examine whether the shape of an emotion is able to determine when this emotion is a correct response to an object. At first sight, the shape of emotions seems to be the tool that is needed. Presented with various reasons in favor of or against an emotional response towards a given object, the shape is supposed to tell us which considerations we should exclude. Hopefully, we will eventually be left with the reasons - that is the features of an object - that make an emotion fitting. One has 
a the right kind of reason for experiencing an emotion if the object of the emotion has the property that characterizes the shape of this emotion type. Once again, this seems to be the general point that leads us to see moral and prudential features of a joke as irrelevant to our assessment of the correctness of amusement as a response to it.

However, this shape criterion raises a general concern, because it is in fact useless in deciding which features are really relevant. This becomes particularly clear when one wonders how to apply this criterion. Let us assume that practical considerations are irrelevant in assessing what is amusing. Now, if prudential and moral considerations are considered irrelevant, then aesthetics, intellect, originality, and a number of other considerations must also be discarded because they are similarly irrelevant to determining what is amusing simpliciter. To put this point conditionally, if the defenders of shape criterion reject moralism and what we may call prudentialism, they must also reject aestheticism, intellectualism, and the like. If whether or not a joke is immoral or dangerous is irrelevant to its being amusing, why should its intellectuality or originality be relevant? Since we are looking for what is amusing, and not for what is intellectually amusing or originally amusing, the shape criterion seems to exclude all of these features as giving us reasons to be amused. Worse, the problem is generalizable to any feature that could be envisioned: one may suggest that what is amusing must be trivial or not, have an artistic element or not, some originality or not, etc. But again, none of these features can be legitimately accepted by the shape criterion. Even if there are natural features on which aesthetic value, intellectual value, or originality supervenes, it remains the case that none of these features. nor any combination of them, can be considered reason for being amused simpliciter. The conclusion that we are compelled to draw is that 
if the shape criterion seems at first sight to exclude some features, then no feature is able to resist this strategy of exclusion.

As an analogy, and for what it is worth, the shape criterion appears to operate as a constraint that we believe could help dispense with the peelings to locate the fruit itself; that is, to shed irrelevant considerations in order to discover the right kind of reasons and hence the features that make something truly amusing. To our surprise however, we are peeling an onion; when we remove all of its layers, nothing remains. Every single consideration to which you may appeal in order to argue that an amusement fits an object may in fact be excluded by the shape criterion, since there is nothing that can explain why only certain considerations should not be excluded. The conclusion is thus that it is impossible to justify that certain amusements are correct through reliance of the shape of amusement.

At this point, friends of the epistemic approach will certainly insist that there are features that make it correct to be amused by a joke and that these are precisely the features, intellectuality or whatever, on which amusingness supervenes. Nevertheless, the problem is that they must explain, at least in principle, why, say, a certain degree of intellectuality or originality — the reader is free to chose his or her favorite feature - is relevant, whereas moral considerations are irrelevant. The problem is that there is apparently nothing that can legitimize such a choice, because shape is completely uninformative with regard to these choices. It is worth emphasizing that this problem is not specific to the emotion of amusement. We may disagree on what is really enviable, shameful, or even fearsome and again, these concepts do not offer in and of themselves any way to reduce the divergence of our responses and judgments. The concept enviable 
does not exclude enviable wealth or enviable success, etc. But if it does not, how could we determine what is truly enviable? To take an extreme case, we may even ask why prudential considerations are relevant with regard to fear. If the shape of fear is fearsome, then this shape in and of itself does not answer the question raised. Things may be fearsome without being dangerous. We certainly think of some movies as fearsome. Should we exclude them? But why? Here, it becomes difficult to avoid asserting that it is for prudential reasons, but this is precisely what the epistemic approach seeks to deny.

It seems to me symptomatic of this difficulty that the examples given by D'Arms and Jacobson lack coherence. On the one hand, they claim that moral and prudential considerations should be excluded when considering the reasons that would make amusement and shame correct. We should neither moralize nor "prudentialize" their shape. However, on the other hand, they claim that prudential considerations are relevant when we consider fear. But what is the coherence underlying these examples? If shame fits objects that are not moral, why could fear not fit objects that are not prudential? I suppose that the answer is that the shape of shame is not moral, whereas the shape of fear is prudential. But this is precisely the point that requires justification. The concept shameful does not deliver more information about what features should be excluded than fearsome does. Indeed, they give us none.

But are we not mistaken about these shapes? Do we not have such a justification if fear presents its object not as fearsome but as dangerous? Yes, if this were the case, then all of the difficulties that we have raised would disappear. However, we must observe that the object of the vast majority of emotions with which we are concerned are 
evaluatively presented or judged as having response-dependent properties or concepts: shameful, amusing, despicable, exciting, joyful, etc. Thus, it is certainly false in general that our emotions present their object as having response-independent values that would allow us to avoid the problem that we have just raised. This in turn suggests that the shape of fear is not dangerous but fearsome, because it is very implausible that the shape of fear would be of a different type than other emotional shapes. If this is correct, then we are again stuck with our problem.

However, it could be argued that even if the evaluated content of our emotions involves response-dependent values, the appraisal process that produces our emotions assesses whether objects have response-independent values. Evolutionary considerations are certainly in favor of such a hypothesis since it is highly plausible, for example, that our dispositions to experience fear and disgust are efficient responses to two different types of danger that we may face in our environment. Moreover, this is compatible with what we have just said, since we may not be aware of this assessment. In any case, and even if we conceded that we are aware of the assessment that underlies our emotions, this would not be good news for the epistemic approach, for it means renouncing the FAA of emotional value concepts. Indeed, if what makes an emotion of fear correct is the fact that its object is dangerous, then the correctness of fear eventually relies on a value that is understood independently of fear. In this case, we would have a very clear grasp of the correctness of an emotion since we would understand it as the correctness of the perception of response-independent values of the world. Admittedly, this renouncement is not incoherent. but it is incoherent to exploit it in defense of a version of the FAA of emotional value concepts. 
In other words, the epistemic approach cannot have the best of both worlds. It cannot rely on an interpretation of the fear example to convince us that there is an obvious way in which emotions are objectively correct, and then shift to amusement in order to convince us that the epistemic approach to the FAA concerns responsedependent emotional value concepts. Either the epistemic approach considers that the shape of an emotion type presents its object as having a response-independent value in order to show that some emotion tokens of this type are correct and it is no longer a FAA analysis, or the epistemic approach wants to count as a FAA, in which case the shape criterion is unable to legitimately say which emotions objectively fit their objects.

\subsection{Emotional dispositions and discounting practice}

But have we been looking in the right direction? The defender of the epistemic approach may acknowledge that the shape of emotions is not sufficient to explain why an object makes a response correct while insisting that our emotional dispositions contribute to this explanation. A look at the perception of color unquestionably supports this suggestion. It has been rightly emphasized that the conditions that make a redness experience correct need not be known a priori through the notion of redness. ${ }^{25}$ Experience teaches us that the circumstances in which our exposure to red is normal, and we probably also learn from experience that it is precisely in these normal cases that we correctly apply the concept red. Similarly, it may be argued that what is amusing is at least partly defined by considerations that are external to the shape of amusement. However, although the point is fully in place while we consider the concept red, it would be a mistake to carry this over to the realm of evaluative concepts. The general problem is that our normal 
emotional responses cannot provide any justification for their fittingness. Therefore, we lack the kind of justification on which we rely in the case of color.

In response to this general concern, D'Arms and Jacobson have emphasized, following Wiggins and Pettit, that our practice of judgment about emotional values also includes a discounting practice that discards some of our emotional responses as improper grounds for emotional value judgments. ${ }^{26}$ In an effort to be more precise about this discounting practice, they have identified several "obscuring factors" such as sensitization, mood effects, or the presence of other emotions that block or facilitate an emotional response or our attitude towards the teller or the butt of a joke. I do not wish to deny that such factors play a role in our emotional response and, moreover - at least for the sake of the argument—, that they justify discarding emotions biased by these factors. Yet, I want to suggest that aside from these factors, others are part and parcel of our sensibilities and thus cannot be excluded. In other words, I claim that certain factors are responsible for our different emotional responses and the diverging judgments that follow these emotional responses without being "obscuring factors".

Suppose that I explain in part and correctly my laughter by the intellectuality of a joke, and that my opponent explains in part and correctly his absence of laughter by saying it is not sufficiently original. Where does this lead us? We may both exclude these considerations or both include them, but I am unable to see on what basis we could make a non-arbitrary choice between them. Or consider another feature: the sexual aspect of jokes. Certainly, our disposition to laugh at jokes with a sexual component depends on our sexual orientations and general approach to sexual matters. But where is the correct response? How should we deal with these differences? Even if we neutralize sexual 
orientations, there will still be differences that should not be neutralized. For surely, if we neutralize not only our divergent beliefs, as D'Arms and Jacobson suggest, but also our different desires and thus our different emotional dispositions, then we would certainly have the same sense of humor, but this result is trivial and useless. Doubtless, if we have all had the same education and have the same desires, we would make the same judgments about what is amusing. But, even if it may be conceded that some of our desires may be obscuring factors, our general, long-term dispositions with regard to sexual matters should certainly not be considered obscuring factors but integral parts of our sensitivities. Therefore, they should certainly not be neutralized as irrelevant. Thus, even if there are obscuring factors, our judgments purified of all the obscuring factors are still largely divergent, and neither shape nor our dispositions provide us with the means to overcome this discrepancy. A similar point may be made about envy. Some of us are envious of our relatives, and others of people who are not as close. Some of us may be envious of success, while others envy other people's peace of mind. I believe that at least some of these differences are part of our sensitivities and thus, that our disagreements cannot be overcome.

It might seem that there is still an answer. Why not accept that every possible non-obscured amusement is fitting? Why not adopt ecumenism? However, this proposal faces a serious objection. On this view, everyone has a reason to experience amusement in response to a joke as soon as there is one person who is amused by this joke without being obscured. ${ }^{27}$ This seems to me in itself a problematic thesis. However, the FAA of emotional value must reject it, because this analysis presupposes that value concepts are 
dependent on our emotional dispositions. Indeed, one of the major attractions of the FAA of emotional value concepts is that it implies that what is amusing depends essentially on our dispositions to be amused. ${ }^{28}$ This explains why the emotional values of these analyses are anthropocentric: if our dispositions were different, we would have other values. In other words, if human beings are unable to respond with amusement to certain objects, then these objects cannot be amusing. Now, the same point must, for parity, be applied to individuals. If someone is unable to be amused by certain jokes, then they cannot be amusing for him; hence this person has no reason to be amused.

It may be replied that the actual dispositions of a person are not relevant. Rather, it is only required for an individual to have a reason to be amused by a joke for him or her to be able to acquire the disposition to be amused by this joke. This much may be conceded, but it is not sufficient to salvage ecumenism. Our dispositions to be amused are certainly not plastic enough to give us reason to be amused by all of the jokes that amuse (without obscuring factors) at least one human being; as we get older, we certainly find it more difficult to acquire the disposition to laugh at what we found so funny in our youth. In general, our sense of humor is a very complex consequence of our lives, our ways of thinking, and our backgrounds. How could we change all that? I believe therefore that we must accept a more modest view, to the effect that we have reasons to be amused by only a subset of all of the jokes that human beings are able to enjoy. Hence, the incongruity of a joke cannot give all of us a reason to be amused. Even if we take account of our dispositions, we cannot overcome our divergent, non-obscured emotional responses. We are therefore driven to the same conclusion: the epistemic approach fails because it supposes that there are objectively amusing jokes whereas there are none. 
As a last resort, it may still be objected that even if it is difficult to find a criterion for good jokes, it is nevertheless indisputable that it is false that any sentence could make a good joke from a certain point of view. For instance, "I have an apple and I eat it" is certainly not a good joke. It seems objectively true that it is not amusing. Therefore, even if we are presently ignorant of precisely what makes a good joke, we clearly feel that some jokes are not good. Thus, there must be a criterion for good jokes that our example would not satisfy. However, the intuitive force of this objection is based on a misunderstanding. The point that I have made does not imply the extreme view according to which there is a point of view from which any sentence is amusing. It suffices for my objection to stand that there are no objective criterion that overcome at least some divergent dispositions to be amused. It is not required that we all diverge on any sentence, nor that at least one human being be disposed to laugh at any next sentence. Insisting on remaining divergences does not commit us to the extreme view. Conversely, the falsity of the extreme view has no bearing on the idea that some divergences will remain even after we acknowledge that some emotional responses will be discarded because they are influenced by obscuring factors.

We can therefore conclude that, even with the further aid provided by our natural dispositions and our discounting practice, the shape criterion is not able to avoid the legitimacy of divergent response. In a nutshell, no emotions are objectively fitting. Hence, the epistemic approach is nothing other than an error theory: an analysis for concepts of emotional values that are not instantiated. 


\section{Fitting emotions and practical considerations}

\subsection{Shape and fitting objects}

Given the results of the previous section, the complementary aim of the present section is to show the role of practical considerations in explaining the fittingness of emotions. In order to do so, I am going to present a second argument against the epistemic approach that explains why this approach is unable to provide satisfactory grounds for our judgments on the fittingness of emotions. But first, a significant distinction must be drawn between the notion of shape and the notion of fitting object. Indeed, we use these notions--but also the notion of formal object--to characterize, in general terms, both the kind of assessment involved in an emotion type and the objects which this type of emotions fits. We say that amusement assesses a situation as amusing and also that amusement fits a situation if and only if the situation is really amusing. Thus, the same axiological property defines the shape of the emotion and the fitting objects of the emotion. But this way of talking conceals a distinction that must be made at least in principle, since it is one thing to characterize the assessment process that is involved in an emotion type in general terms, and another to give a general characterization of the situations that make this emotion type fitting.

This distinction is made more obvious when we try to characterize more precisely, on the one hand, the constitutive features of the shape of an emotion and, on the other, the constitutive features of its fitting objects. In fact, these are two very different research programs. If we look first at the shape of an emotion, that is the assessment it involves, then we are looking at the features that are necessary and sufficient for an object to be assessed as enviable and to trigger an emotion of envy; we 
are also looking at how it can be modified by learning processes and its variations for different people. This is the research program of the appraisal theory of emotions. It is an empirical task since we are trying to understand the functioning of an assessment system and, as such, it cannot deliver any norm even if the assessment system categorizes, and maybe also presents, objects as being enviable, shameful, admirable, amusing, etc. It is when we are working on this task that we may say, as D'Arms and Jacobson have stated, that it is a mistake to moralize the shape of shame because we must not consider a priori that moral considerations are always relevant for something to be assessed as shameful. On the other hand, this program is completely different from the one whose aim is to identify which objects an emotion type fits, since this latter program is obviously normative. For instance, it is a completely different question whether shame fits only if one is morally blameworthy. When we wonder whether shame fits non-moral objects, the question focuses on the fitting objects of shame themselves rather than on its shape. Similarly, the shape of envy does not prejudge that envy fits some objects. It is certainly not sufficient to say that enviable is the shape of envy to prove that there are at least some objects to which envy fits. Although the assessment underlying envy may categorize certain objects as enviable, it does not follow that envy fits to these objects.

This being said, there is a question that both defenders of the epistemic approach and their objectors must answer: whether the shape of an emotion is relevant and if so, to what extent it is relevant in determining the objects that an emotion fits. The epistemic approach argues either that the shape is the only relevant consideration or that it is relevant in combination with our emotional dispositions and discounting practice. On the 
contrary, I want to suggest that these elements are completely irrelevant and that we should rely exclusively on practical considerations.

In fact, this latter suggestion is entailed by the strict distinction that we have just drawn between the shape of an emotion and its fitting objects. To put the point dramatically: the distinction entails that it be perfectly possible for the shape of envy on the one hand to present certain objects as enviable, even if on the other hand envy does not fit any object. This would be the case if there were neither moral nor prudential reasons to be envious in response to any object, and, if in addition it were relatively easy to leave the disposition to be envious behind us. Therefore, to argue that envy fits at least some objects because we have a disposition to experience envy and because there is an evaluative process or an evaluative presentation involved in envy is just turning facts into norms. Hence, the justification of the fittingness of an emotion must rely on something different from its shape, the nature of our dispositions to experience the emotion, and the discounting practice. What I will try to show in the remainder of the paper is that we must and do rely on practical considerations in assessing the fittingness of emotions.

In fairness to D'Arms and Jacobson, it must be said that they reject what they call "crude sentimentalism" in favor of a "rational sentimentalism" because, in their view, "normal human emotional tendencies can be criticized and rejected." 29 Their account thus leaves space for a contrast between the shape of an emotion and the objects that this emotion fits and thereby evade my objection. However, it seems to me that the considerations to which they refer, and which are supposed to contribute to determine whether and when an emotion fits, are practical and that they renounce thereby to the epistemic approach, since the general idea is that emotions are fitting when they concur 
with general concerns—-wide concerns" as they put it—-that cannot be eliminated, or not without a high cost, and are "firmly enmeshed in our web of psychological responses".

\subsection{The revenge of prudential and moral considerations}

In this and the following sections, I argue that practical considerations can justify why emotions fit their object when they do. By the same token, it will appear that some of these considerations contribute to our intuitions about this fittingness. Consider again the case of fear. Doubtless, fear fits dangerous circumstances. Thus, the fittingness of fear in dangerous circumstances is a very strong argument in favor of an objective version of the FAA of fearsome. But why does fear fit danger? Danger threatens positive values such as health, life, and happiness, and being afraid facilitates and prepares responses such as fleeing, facing, or attacking that help to confront danger. It is therefore difficult to avoid saying that it is by virtue of prudential reasons that fear fits danger. Moreover, there are different forms and degrees of fear, and they may themselves more or less fit their objects. But again, forms and degrees of fear fit their object for prudential reasons. Thus, our intuitions about the fittingness of fear contrast radically with our intuitions about amusement. It seems that it is the practical relevance of the emotion that makes it fitting rather than its shape. Notice, by the way, that we would then move from the empty assertion that fear fits the fearsome to the informative assertion that fear fits danger through prudential considerations: it is by reflecting on the practical use of fear that we can overcome the indeterminate answer offered by the shape criterion about its fitting objects and reach an informative one. 
Nevertheless, friends of the epistemic approach have an answer. In their view, fear does not fit danger primarily for practical reasons. Rather, fear is the correct response to danger and thus fits danger either because the shape of fear is danger or because its shape is fearsome, but our discarding practice shows that it is only in response to danger that fear is fitting. To support their view, they emphasize that responding with fear to a dangerous object is not always the most prudential response available, but that there is nevertheless a way in which the response fits the object. ${ }^{30}$ For instance, being afraid of a dog is not always the most prudential response. Conversely, the courageous warrior may not experience fear in the midst of battle, even though fear would in this case constitute a correct response. $^{31}$

I contend, though, that these intuitions and descriptions are fragile. On the one hand, it seems quite implausible that brave warrior experience no fear, since it might be argued on the contrary that his fear spurs rather than impedes his bravery. Thus, we can maintain that he should be afraid and that this fear would be prudentially fitting. I cannot really make sense of a brave warrior who experiences no fear at all in the face of true danger. On the other hand, if we insist that he experiences no fear at all, it may be because the situation is not dangerous for him even if it would be for an inexperienced warrior. But if the situation is not dangerous for him, then it is not true that fear would fit the situation. Therefore, either way, the idea of an appropriate but useless fear is objectionable. The situation is truly dangerous, and fear is prudentially advisable, or it is in fact not dangerous, and fear is inadvisable.

But what about the dog? First, even if it is more prudent to have no fear when you are near the dog, it is still true that it is generally more prudent to stay away from dogs as 
long as we are not confident in our ability to deal with them. Thus, their being dangerous still gives us a prudential reason to be afraid. Second, if there is really nothing to fear as long as you are not frightened, we may conclude that in this case, being afraid is not the prudential response and therefore not the fitting response. Thus, in both cases, it may be argued that whenever a fear response is fitting, this fittingness can be explained in terms of prudential responses.

In addition, it must be remembered that the epistemic approach is able to make this case directly only if the shape of fear is danger, and we have seen that this is doubtful. On the other hand, if the shape of fear is fearsome, then the defender of the epistemic approach needs to explain why fear fits only to dangerous objects and why fear in response to non-dangerous objects is discarded. It seems to me that the only explanation is that being afraid of non-dangerous objects is prudentially inappropriate while it is not inappropriate in response to dangerous objects. But if we ultimately rely on such practical considerations to determine which experiences of fear are fitting, then it shows that the epistemic approach needs practical considerations in order to take flight, which is the ruin of this approach. In effect, if the correctness of emotions is ultimately explained through practical considerations, then they are doing the real work, which is to relinquish the epistemic approach.

\subsection{Further practical reasons}

D'Arms and Jacobson have contended, in opposition to any practical approach, that if the fittingness of envy were grounded in prudential or moral considerations, then we would be led to conclude that envy is never fitting. To the extent that this conclusion is 
intuitively false, they claim that the fittingness of envy cannot be explained by relying on prudential considerations. If correct, such an argument could be applied to most emotions, if not to all. Indeed, prudential considerations seem to advise us to always avoid negative emotions such as envy, shame, or grief and on the contrary to always experience joy, excitement, admiration, and fun. However, as the example of fear has shown, it would be overly simplistic to conclude that there is no general prudential reason to be disposed to experience negative emotions. On the contrary, it seems to me quite easy to show that practical considerations explain both the fittingness and the unfittingness of negative emotions in response to various objects. To begin with, it is clear that extreme envy and grief are unfitting because they are useless and obsessive suffering. Arguably, therefore, the considerations that justify the lack of fittingness of extreme envy and grief are once again practical. Moreover, it is very plausible that our intuitions about the lack of fittingness of extreme envy and grief are grounded in these prudential considerations. Now, this practical consideration may lead us to believe that these emotions and the dispositions underlying them cannot be prudentially beneficial on the whole. However, this would be grossly mistaken. Consider the case of envy. It may be argued, in agreement here with D'Arms and Jacobson, ${ }^{32}$ that a life without envy is less pleasant as a general matter. Several reasons may support this hypothesis. First, the annihilation of envy may entail the abandonment of desires whose fulfillment is attainable and that are elements of a good life. Is a life in which we would not long for the satisfaction of some of our desires preferable to one in which we would experience such a longing? Second, envy may contribute to the meaning of a life oriented around goals that are enviable and attainable. Similar considerations may be adduced with regard 
to grief and sadness, for example. Although we have prudential considerations that suggest avoiding them as such, we also have prudential considerations indicating that we should lead a life that exposes us to them. We are certainly tempted to think that someone who experiences very little grief at the death of a close relation was not truly involved in the relationship and may lack the sensibility that might be advisable to have a meaningful life.

Symmetrical arguments may be given with regard to the justification of the fittingness of positive emotions. Because positive emotions are pleasant, we have a general prudential reason to experience them as much as possible. In addition, there are certainly broader prudential benefits in having them. For instance, it seems quite plausible that having objects of admiration contributes to providing meaning to our lives. The same goes for objects that makes us laugh. Therefore, we have general prudential reason to be disposed to experience positive emotions. However, these dispositions cannot be extended without limits. It is not humanly possible to experience joy in response to every object. Moreover, a life with too much admiration may be linked to a tendency to lack self-esteem, as the disposition to laugh too easily may be a symptom of influenceability. Thus, one may say that our experience of admiration and amusement are fitting if they result from dispositions that are on the whole beneficial to our lives. On the contrary, admiration, and amusement in response to certain objects are unfitting if their underlying dispositions contribute to our lives by worsening them.

This general thesis to the effect that the fittingness of our emotions can be understood in terms of prudential reasons may be objected to in the case of negative emotions such as shame and guilt, for which it may be difficult to see what is beneficial 
in the disposition to experience shame and guilt. This seems to be correct. However, it seems to me very plausible that our intuitions about the fittingness of these emotions rely on moral considerations. Shame fits certain circumstances because it is morally required and conversely, shame is inappropriate if one has done nothing wrong. D'Arms and Jacobson disagree and insist that we should not moralize the shape of shame: shame also fits non-moral objects. As they themselves admit, it follows that being ashamed of one's disability is a fitting response. But in my view, if a value theory has such a consequence, then this is a strong argument against it. Not only do I believe that we have no moral reason to be ashamed of our disabilities, it also seems to me that it should follow that we have, in general, no reason at all to be ashamed. Moreover, I am inclined to believe that this most people would agree that the disabled should not be ashamed of their handicap. Therefore, it seems that the practical approach, on this matter at least, is more commonsensical than the epistemic approach.

\subsection{The possibility and the cost of change}

To the practical reasons thus far considered, two considerations that affect them should be added. The first is encapsulated in the "ought implies can" principle (hereafter OICP), and the second derives from the fact that even if it is possible to change our dispositions, this also has a cost. The first consideration may defeat or limit our prudential and moral reasons, while the second may have only a limiting effect. Consider again envy. As has already been argued, envy is an unpleasant emotion that may furthermore lead us to do what we should not do. But, although we have prudential and moral reasons not to be too envious, it may be impossible or very costly to change our disposition to envy, and it is 
quite plausible that these considerations affect our judgments about the fittingness of envy. Thus, the OICP entails that the practical reasons to eliminate envy are diminished—or limited—asthe possibility of eliminating the emotion itself diminishes. In other words, certain envy may be prudentially acceptable, if not recommendable.

Interestingly, I believe that the role played by these considerations shows itself in the asymmetry that characterizes our judgments of fittingness. Indeed, the OICP and the cost of change provide only defeating or limiting reasons that somehow diminish the force of our practical reasons for avoiding envy; they do not provide positive reasons to experience envy. They never recommend envy but only make it acceptable to some extent. Therefore, if the OICP and the cost of change contribute to grounding our intuitions about the fittingness of emotions, they should be an asymmetry in these judgments. As it happens, this appears to be precisely the case: we have clear intuitions about the lack of fittingness of excessive envy whereas we are much less prone--to say the least--to judge someone who is not envious at all or very rarely as being insufficiently envious. Thus, it is quite plausible that our intuitions about the fittingness of emotions are partly influenced by our—at least implicit—commitments to something like the OICP and cost of change.

In addition, these two limiting considerations might explain our tendency to consider that normal emotional responses are more appropriate. Indeed, it is quite tempting to believe that it is more difficult to eliminate idiosyncratic than normal responses. After all, if some responses are idiosyncratic, they have certainly been learned, and it is therefore tempting to surmise that they could more easily be unlearned than more common responses. Thus, the plausible belief that our normal emotional dispositions are 
the most anchored may contribute to the common belief that the more ordinary responses are also the least unfitting.

In summary, I claim that prudential and moral reasons in combination with the OICP and the cost of change contribute to some extent to our intuitions about the fittingness of emotions. Furthermore, I claim that these considerations alone are entitled to satisfactorily justify our judgments about the fittingness of emotions and that they are able to provide a complete account of this fittingness. Hence, I believe that a practical approach of the FAA in which the fittingness of emotions is the result of practical considerations, and only of practical considerations, should receive more thorough consideration. Nevertheless, I do not deny that such an approach is partly revisionist. Indeed, I am convinced that our intuitions about the fittingness of emotions also rely on the belief that it is possible to find an objective epistemic criterion for what is objectively amusing, admirable, etc., even though I have just argued that this last belief is incorrect. Moreover, it is important to note that even if I am on the right track, I am not suggesting that any practical reason in favor of an emotion is relevant to its fittingness. Indeed, the demon's case still requires a criterion that excludes the wrong kind of reasons. Therefore, in order to fully appreciate whether a practical approach to the FAA is viable, we need a criterion that would solve the WKR problem. In this paper, I have only been arguing that the relevant criterion must draw a distinction within practical reasons. Although it is beyond the scope of this paper to provide such a criterion and to thoroughly assess it, it seems that for a practical reason to be relevant to the fittingness of an emotion towards an object, this reason for feeling the emotion as regards the object 
must hold, at least defeasibly, in some sort of general circumstances, or maybe in a certain relevant set of general contexts. I am, however, going to leave this discussion for another occasion. Instead, I would like to consider two consequences of the practical approach to the FAA.

\section{The practical approach to the FAA and emotion-able concepts}

The first consequence concerns the concepts analyzed by the FAA. These concepts are presented in the literature as concepts of value. However, as we have already emphasized in section 1, if the reasons relevant in to the analysis - the right kind of reasons - are practical, then the concepts that are analyzed are no longer concepts of value. If $\mathrm{X}$ is fearsome means that there are general (and maybe defeasible) prudential reasons to be afraid of $X$, then $X$ itself is at best an instrumental value. Similarly, if " $X$ is shameful" means that there are moral reasons to be ashamed of $\mathrm{X}$, then $\mathrm{Y}$ is not a value in itself but something to which we should respond in a certain way for moral reasons. Does this imply that we should give up the FAA of these concepts? I do not think so, because it can still be argued that the FAA is analytically true. In any case, the rejection of the epistemic approach to the FAA does not force us to give up the general structure of the FAA. Rather, my point has been only to argue that a practical approach is preferable to the epistemic approach if we stick to a FAA. If I am on the right track, then it follows that admirable, shameful and all emotion-able concepts are either normative concepts or concepts of instrumental values. The role of these concepts is then to give general advice about emotions in response to objects by virtue of practical considerations and apart from the further consideration of the very specific context in which one may find oneself. 
Hence, "X is fearsome" does not mean that there is a value named "fearsome" in response to which fear is correct, i.e., that gives us a reason to be afraid that is primarily epistemic. Rather, it means that $\mathrm{X}$ is such that there are general prudential but defeasible reasons to be afraid of it.

The second consequence concerns the objectivity of the FAA on its practical approach. We have argued that there are objective practical reasons that justify the fittingness of fear and maybe of emotions such as shame. However, when we have considered envy, grief, and positive emotions, we have argued that the fittingness of these emotions depends on prudential reasons, some of which are limited by the OICP and the cost of change. If this is accurate, then it implies that these prudential reasons justify different emotional responses according to one's emotional dispositions. For example, given the general benefit of being amused, someone has prudential reason to be amused by a joke if they have the disposition that allows them to be amused by it, or if there is a possible and not too-costly evolution of their disposition to be amused that would make them responsive to such jokes and that would enhance their life. It may be that they have a too rigorous way of life to which they have no reason to stick. The same goes for prudential reasons that rely on the OICP and that make the experience of envy acceptable to a given extent. If an excessive level of envy is globally detrimental to a good life, the precise disposition to envy that are acceptable from a prudential point of view depend on one's present disposition to experience envy. Our current dispositions constrain the potential paths that could lead to a life with less envy, if indeed such paths exist. In a nutshell, the introduction of prudential reasons and of the OICP entails that the fittingness of emotions is relative to individuals because these reasons are relative to the specific 
emotional dispositions of individuals, to the path available for a change, and also to other aspects of their personality that may affect the possibility of change or its cost. Therefore, the formulation of the FAA of a normative emotional concept $\mathrm{Y}$-able linked to an emotion Y may be stated in two different forms. It may be stated in apparently objective terms along the following lines: $\mathrm{X}$ is $\mathrm{Y}$-able if and only if there are general (and maybe defeasible) practical reasons to $\mathrm{Y}$ in response to $\mathrm{X}$. However, insofar as the individual emotional dispositions that ground the prudential reasons and its defeaters and modifiers are different, it follows that these reasons are not objective, i.e. that they do not apply equally to everyone. Therefore, a more explicit formulation would be: $\mathrm{X}$ is $\mathrm{Y}$-able to an individual A if and only if there are general (and maybe defeasible ) practical reasons (among which some are relative to the emotional dispositions of A) for A to experience $\mathrm{Y}$ in response to $\mathrm{X}$.

\section{Conclusion}

The purpose of this paper has been to propose modifying the approach to the FAA of emotional value concepts. Several defenders of the FAA of emotional value concepts have suggested that the relevant reasons must be somehow independent from practical considerations that bear on the emotion itself, and that the notion of fittingness must be understood as an epistemic notion. However, I have argued that neither the shape of an emotion nor our emotional dispositions, nor even a discounting practice that would not rely on practical considerations, is able to offer legitimate grounds to decide when an emotion is objectively correct. The epistemic approach thus leads the FAA to an error theory. In the second part of the paper, I have tried to revive the possibility that the 
relevant reasons in the FAA must be practical. Hence, I have devoted significant effort to showing that practical considerations are sufficient to satisfyingly ground the fittingness of emotions. The general idea — using Brentano's vocabulary against his own view—is that love is not fitting because its object is correctly assessed as loveable, but because in loving this object we are improving our life from a practical point of view. An important consequence of this view is that that there is no point in deciding which jokes are objectively funny because the funniness of jokes is relative to individuals. However, accepting this relativism does not prevent us from being mistaken in our amusement, as in our love, if the object of our amusement or love could be changed for a better life. My claim is that this is the only kind of criticism that does not simply convert facts into norms.

\title{
References
}

\author{
Bykvist, Krister
}

2009 No Good Fit: Why the Fitting Attitude Analysis of Value Fails. Mind 118:1-30.

Brentano, Franz

1969 [1889] The Origin of our Knowledge of Right and Wrong, ed. Oskar Kraus and Roderick Chisholm, trans. Roderick Chisholm and Elizabeth Schneewind. London: Routledge \& Kegan Paul.

Chisholm, Roderick 
1986 Brentano and Intrinsic Value. New York: Cambridge University Press.

Danielson, Sven and Olson, Jonas

2007 Brentano and the Buck-Passers. Mind 116: 511-22.

D'Arms, Justin \& Jacobson, Daniel

2000 The Moralistic Fallacy: On the "Appropriateness" of Emotions.

Philosophy and Phenomenological Research 61 (1):65-90.

2006 Anthropocentric Constraints on Human Value, in Shafer-Landau (eds.)

Oxford Studies in Metaethics 1. Oxford: Clarendon Press.

2010 Demystifying Sensibilities: Sentimental Values and the Instability of

Affect, in P. Goldie (ed.) Oxford Handbook of Philosophy of Emotions,

Oxford, Oxford University Press.

Ewing, Alfred C.

1939 A Suggested Non-Naturalistic Analysis of Good. Mind 39: 1-22.

Goldie, Peter

2000 The Emotions. Oxford, Oxford University Press.

Lang, Gerald

2008 The Right Kind of Solution to the Wrong Kind of Reason Problem.

Utilitas 20 (4): 472-489.

Olson, Jonas

2004 Buck-Passing and the Wrong Kind of Reasons. Philosophical Quarterly 54: 295-300.

Parfit, Derek 
2001 Rationality and Reasons. In Egonsson, D., Josefsson, J. Petersson B., and Ronnow-Rasmussen, T., (eds.) (online resource) Hommage à Wlodek : Philosophical Essays Dedicated to Wlodek Rabinowiz. Lund: Lund University. Available at www.fil.lu.se/hommageawlodek.

Pettit, Philip

1991 Realism and Response-Dependence. Mind 100.4: 587-626.

Rabinowicz, Wlodek \& Ronnow-Rasmussen, Toni

2004 The Strike of the Demon: On Fitting Pro-Attitudes and Value. Ethics 114 (3): 391-423.

Roberts, Robert C.

2003 Emotions, An Essay in Aid of Moral Psychology. Cambridge: Cambridge University Press.

Scherer, Klaus R., Schorr, Angela and Johnstone, Tom (eds.)

2001 Appraisal Processes in Emotion. Oxford: Oxford University Press.

Skorupski, John

2007 Buck -Passing about Goodness, in Egonsson, D., Josefsson, J. Petersson

B., and Ronnow-Rasmussen, T., (eds.) (online resource) Hommage à

Wlodek: Philosophical Essays Dedicated to Wlodek Rabinowiz. Lund:

Lund University. Available at www.fil.lu.se/hommageawlodek.

Smith, Craig A. and Kirby Leslie D.

2001 Toward Delivering on the Promise of Appraisal Theory, in Scherer, K. R., Schorr, A. and Johnstone, T. (eds.) Appraisal Processes in Emotion. Oxford: Oxford University Press. 
Solomon, Robert C.

1993 The Passions. Indianapolis: Hackett.

Stratton-Lake, Philip

2005 How to Deal With Evil Demons: Comment on Rabinowicz and RonnowRasmussen. Ethics 115: 788-798.

Tappolet, Christine

2000 Emotions et valeurs. Paris : Presses Universitaires de France.

Wiggins, David

1987 A Sensible Subjectivism? in Needs, Values, Truth: Essays in the

Philosophy of Value. New York: Oxford University Press, 185-214.

\footnotetext{
* I am grateful to Christine Tappolet and Cain Todd for their very helpful comments on a previous version of this paper and to Nadja Berrebi and John Angell for their editorial assistance with the manuscript.

${ }^{1}$ Bykvist (2009).

${ }^{2}$ For views along these lines, see Brentano (1969), Tappolet (2000), D'Arms and Jacobson (2000, 2006), Olson (2004), Danielson and Olson (2007).

${ }^{3}$ Ewing (1939) suggests that "ought" is the alternative that should be chosen. Note, however, that Ewing distinguishes this "ought" from what he calls the "moral ought". Chisholm (1986) proposed the plausibly very close if not identical notion of "requirement".

${ }^{4}$ See Rabinowicz and Ronnow-Rasmussen (2004). In fact, the problem was first raised by D'Arms and Jacobson (2000), who call it the "conflation problem".
} 
${ }^{5}$ For simplicity, I will avoid systematically stating this disjunction and will express myself as if fittingness can always be expressed in terms of reasons. In any case, this is not a presupposition of the paper, and I will return to the disjunction when necessary. ${ }^{6} 2000: 66$.

${ }^{7}$ Parfit (2001).

${ }^{8}$ Skorupski (2007).

${ }^{9}$ Lang (2009)

${ }^{10}$ D'Arms and Jacobson (2009:20).

${ }^{11}$ Olson (2004).

${ }^{12}$ Stratton-Lake (2005).

${ }^{13}$ Danielson and Olson (2007).

${ }^{14}$ See Brentano (1969).

${ }^{15}$ I use "object" in the broadest sense to refer to anything to which an emotion may be a response, whether it is a state of affairs, an event, an action, or an object in the strict ontological sense, since this has no bearing on what I have to say here.

${ }^{16}$ This point is held by judgmentalists and perceptualists, but also even by those who hold that although emotions involve an assessment of their objects, the subjects undergoing the emotions are not aware of it.

${ }^{17}$ See, for example, Scherer, et al. (2001) for an overview.

${ }^{18}$ See, for example, Smith and Kirby (2001).

${ }^{19}$ See, especially, Solomon (1993).

${ }^{20}$ See D'Arms and Jacobson (2000), Goldie (2000), Tappolet (2000). 
${ }^{21}$ (Ibid.: 72). Rabinowicz and Ronnow-Rasmussen (2004: 420-422) report and discuss their view.

${ }^{22}$ Both in this volume.

${ }^{23}$ Ibid.: 87 .

${ }^{24}$ Pettit (1991: 603).

${ }^{25}$ Pettit (1991), Tappolet (2000).

${ }^{26}$ See especially D'Arms and Jacobson (2010) who develop a point that has already received attention from Wiggins (1987) and Pettit (1991).

${ }^{27}$ I am indebted to Christine Tappolet on this point, who suggested this possibility in a personal communication.

${ }^{28}$ Note that this is nothing other than reason internalism applied to reason to experience emotion. The discussion that follows should therefore be recognizable to those who are familiar with the literature on the internalism versus externalism debate about reasons. ${ }^{29}$ (2006: 116).

${ }^{30}$ Ibid.: 73 .

31 Ibid.: 85 .

32 Ibid. 